Wearable Sensors for Personal Monitoring and Estimation of Inhaled Traffic-Related Air Pollution: Evaluation of Methods

Peer-reviewed author version

DONS, Evi; LAEREMANS, Michelle; Orjuela, Juan Pablo; Avila-Palencia, lone;

Carrasco-Turigas, Gloria; Cole-Hunter, Tom; Adaya-Boig, Esther; Standaert, Arnout; DE BOEVER, Patrick; NAWROT, Tim; Götschi, Thomas; de Nazelle, Audrey; Nieuwenhuijsen, Mark \& INT PANIS, Luc (2017) Wearable Sensors for Personal Monitoring and Estimation of Inhaled Traffic-Related Air Pollution: Evaluation of Methods. In: ENVIRONMENTAL SCIENCE \& TECHNOLOGY, 51(3), p. 1859-1867.

DOI: 10.1021/acs.est.6b05782

Handle: http://hdl.handle.net/1942/23291 
This document is the unedited Author's version of a Submitted Work that was subsequently accepted for publication in Environmental Science \& Technology, copyright (C) American Chemical Society after peer review. To access the final edited and published work see http://dx.doi.org/10.1021/acs.est.6b05782.

\section{Wearable sensors for personal monitoring and estimation of inhaled traffic-related air pollution: evaluation of methods}

Dons, Evi ${ }^{1,2, *}$; Laeremans, Michelle ${ }^{1,3}$; Orjuela, Juan Pablo ${ }^{4}$; Avila-Palencia, lone ${ }^{5,6,7}$; CarrascoTurigas, Glòria ${ }^{5,6,7}$; Cole-Hunter, Tom ${ }^{5,6,7,8}$; Anaya-Boig, Esther ${ }^{4}$; Standaert, Arnout ${ }^{1}$; De Boever, Patrick ${ }^{1,2}$; Nawrot, Tim ${ }^{2}$; Götschi, Thomas ${ }^{9}$; de Nazelle, Audrey ${ }^{4}$; Nieuwenhuijsen, Mark $^{5,6,7}$; Int Panis, Luc ${ }^{1,3}$

* Corresponding author: evi.dons@vito.be

Address: Boeretang 200, 2400 Mol, Belgium; Phone: +32 14335190 / Fax: +32 14582657

\footnotetext{
${ }^{1}$ Flemish Institute for Technological Research (VITO), Boeretang 200, $2400 \mathrm{Mol}$, Belgium

${ }^{2}$ Centre for Environmental Sciences, Hasselt University, Agoralaan building D, 3590 Diepenbeek, Belgium

${ }^{3}$ Transportation Research Institute (IMOB), Hasselt University, Wetenschapspark 5/6, 3590 Diepenbeek, Belgium

${ }^{4}$ Centre for Environmental Policy, Imperial College London, Exhibition Road, South Kensington Campus, SW7 2AZ London, UK

${ }^{5}$ ISGlobal, Centre for Research in Environmental Epidemiology (CREAL), C/Dr. Aiguader 88, 08003 Barcelona, Spain

${ }^{6}$ Pompeu Fabra University (UPF), C/Dr. Aiguader 88, 08003 Barcelona, Spain

${ }^{7}$ CIBER Epidemiología y Salud Pública (CIBERESP), C/Monforte de Lemos 3-5, 28029 Madrid, Spain

${ }^{8}$ Department of Environmental and Radiological Health Sciences, Colorado State University, Fort Collins, Colorado, USA

9 Physical Activity and Health Unit, Epidemiology, Biostatistics and Prevention Institute, University of Zurich, Seilergraben 49, 8001 Zurich, Switzerland
} 


\section{Abstract}

Physical activity and ventilation rates have an effect on an individual's dose and may be important to consider in exposure-response relationships; however, these factors are often ignored in environmental epidemiology studies. The aim of this study was to evaluate methods to estimate the inhaled dose of air pollution and understand variability, in the absence of a true gold standard metric. Five types of methods were identified: (1) methods using (physical) activity types; (2) methods based on energy expenditure, METs (metabolic equivalents of task) and oxygen consumption; (3) methods based on heart rate or (4) breathing rate; and (5) methods that combine heart and breathing rate. Methods were compared using a real-life dataset of 122 adults who wore devices to track movement, black carbon air pollution and physiological health markers for three weeks in three European cities. Different methods to estimate minute ventilation performed well in relative terms with high correlations among different methods. But in absolute terms, ignoring increased ventilation during day to day activities could lead to an underestimation of daily dose by a factor 0.08 to 1.78 . There is no single best method and a multitude of methods are currently being used to approximate dose. The choice of a suitable method to determine dose in future studies will depend both on the size and the objectives of the study.

Keywords: air pollution, black carbon, physical activity, minute ventilation, inhaled dose, intake, active mobility 


\section{Introduction}

The scientific panel of the Health Effects Institute (HEI) concluded already in 2010 that sufficient evidence is available to support the statement on a causal relationship between traffic-related air pollution (TRAP) and exacerbation of asthma. Further evidence suggests a causal relationship between TRAP and the onset of childhood asthma, as well as other respiratory symptoms, lung function and cardiovascular mortality and morbidity ${ }^{1}$. Though, in large-scale epidemiological studies on which these statements are based exposure assessment at an individual level is often non-specific because it relies on measurements at fixed-site monitoring stations or estimates of ambient air pollution at the home location. Determining exposure more accurately is the best way to enhance our knowledge on exposure-response relationships, and it will help us in quantifying effect sizes more precisely ${ }^{2,3}$. Parallel to the large-scale studies, panel studies in up to a few hundreds of participants have been performed. Panel studies have the advantage that it is feasible to look at specific subclinical health markers, complementing large scale epidemiological studies with clues for mechanistic effects ${ }^{4}$. Study participants can be tracked using mobile devices for air pollution exposure, timeactivity patterns, geo-location, or physical activity levels, and this way limiting exposure misclassification ${ }^{5,6}$.

Recently, research and policy on active mobility in cities, as a means of increasing physical activity levels and health, has intensified. Some health impacts may be worse in cyclists or pedestrians due to the higher dose of air pollution they breathe while being physically active; other effects could be offset by the physiological changes (benefits) associated with an increase in physical activity ${ }^{7-10}$. However, ventilation changes are rarely accounted for in current epidemiological studies: the amount of pollution reaching the lungs and the cardiovascular system is assumed independent from the volume of air breathed. Using exposure instead of dose can cause measurement error and therefore bias exposure-response relationships. Ideally a facemask is used to measure ventilation, but this is uncomfortable and may affect breathing itself ${ }^{11,12}$. Alternatively chest straps and commercially available heart rate and/or breathing rate monitors may provide an opportunity to improve estimates of minute ventilation and inhaled dose in panel studies.

The objective of this paper is to compare minute ventilation and inhaled dose across methods in a panel study, using non-obtrusive, wearable and commercially available sensors. Methods were identified from an extensive literature search while only considering ecologically-valid studies (the settings of the study had to approximate the real world). 
The quantification of inhaled dose is useful for future analyses on the relationship between dose and health outcomes. It will help in understanding exposure-response relationships as a result of being physically active on a daily basis in a polluted environment taking into account increased physical activity as well as increased exposure to air pollution. 


\section{Materials \& methods}

\section{Data collection \& processing}

A panel study was conducted with 122 healthy adult volunteers (approximately 40 participants per city) wearing personal monitoring devices in Antwerp, Barcelona and London during three separate weeks between February 2015 and March $2016^{13}$. Participants were equipped with a microAeth black carbon aerosol monitor (AE51, AethLabs, USA) to measure personal exposure to TRAP on a 5-minute time resolution. They also wore a GPS (I-GOTU GT-600) and a smartphone (Samsung Galaxy SII, Korea) for obtaining instantaneous data on geo-localization and accelerometry. The monitoring kit was extended with two multi-sensor systems combining multiple physiological and mechanical sensors: a SenseWear (model MF-SW, BodyMedia, USA) for physical activity registration, and a Zephyr BioHarness 3 (Zephyr Technology Corporation, USA) for real-time breathing rate, breathing wave amplitude (thoracic movement) and heart rate ${ }^{14}$. Participants carried the devices for seven consecutive days to reflect habitual behaviour over a week; the Zephyr BioHarness was worn only for two days during waking hours because the chest strap was uncomfortable to wear for a longer period. In the beginning and at the end of the week, every participant performed a lung function test using the EasyOne spirometer (ndd Medizintechnik AG, Switzerland) to determine forced vital capacity (FVC) amongst other lung function parameters. Every participant took part in three different seasons - intermediate, cold, warm - mainly to anticipate variations in black carbon concentrations, totalling to 21 monitoring days per participant. Sensor data was cleaned, anonymised and loaded into a central database. For the microAeth, the optimized noisereduction algorithm ${ }^{15}$ was applied together with some additional cleaning to filter out erroneous measurements. The SenseWear (software version 8.0 ) used propriety algorithms to derive activity types and calculate metabolic equivalents of task (METs; the ratio of the energy cost during a specific activity to the energy cost at rest) and energy expenditure. The Zephyr BioHarness collected data on a 1-second time resolution; heart rate and breathing rate data were cleaned according to a number of rules as specified by Bigazzi and Figliozzi ${ }^{16}$. All realtime sensor data was aggregated on a 1-minute time resolution. Only cases with complete availability of all sensors were considered (i.e. coinciding wearing-time periods of microAeth, SenseWear, and Zephyr BioHarness).

Participants gave prior written informed consent, and received a small financial compensation for study participation. This panel study was performed as part of the European project (EU FP7) Physical Activity through Sustainable Transport Approaches 'PASTA' 13, 17. 


\section{Minute ventilation and dose calculation}

Minute ventilation (expressed in $\mathrm{L} / \mathrm{min}$ ) is associated with the metabolic oxygen needs of the body. It depends on personal characteristics such as age, sex, body mass index (BMI), and on activity levels. Exposure was defined as the concentration measured by the microAeth black carbon aerosol monitor near the breathing zone of a person. A dose occurred if a pollutant crossed a physical boundary, i.e. when a human being inhaled or ingested the pollutant ${ }^{18}$. The term dose, as referred to in this manuscript, does not take into account the amount of pollutant that was exhaled again, or expelled from the respiratory tract lining by coughing or sneezing. The inhaled dose was calculated on a 1-minute time resolution as the product of the black carbon concentration and minute ventilation, and then linearly extrapolated to estimate the inhaled dose per day.

Methods to estimate minute ventilation for air pollution exposure assessment were identified from a literature review (Supporting Information), and were then applied to the dataset from our panel study. The methods could be grouped based on available data: time-activity diaries, physical activity level, or direct physiological measures (Table 1).

Table 1: Overview of 16 selected methods used to derive estimates of minute ventilation categorized by method and parameters used.

\begin{tabular}{|c|c|c|c|}
\hline Method & & Source & Formula \\
\hline (Physical) activity & 1.1 & Dons, $2012^{19}$ & Fixed values per activity type (Supporting Information Table S2a) \\
\hline \multirow[t]{2}{*}{ type } & 1.2 & Johnson, $2002^{20}$ & Fixed values per METs level (Supporting Information Table S2b) \\
\hline & 1.3 & $\begin{array}{l}\text { Tainio, 2016; WHO, } \\
2011^{10,21}\end{array}$ & Fixed values per activity type (Supporting Information Table S2c) \\
\hline \multirow{2}{*}{$\begin{array}{l}\text { Energy expenditure, } \\
\text { METs and } \mathrm{VO}_{2}\end{array}$} & 2.1 & Johnson, $2002^{20}$ & $\mathrm{VO}_{2}=\mathrm{ECF} * \mathrm{EE}$ \\
\hline & & & $\mathrm{VE} / \mathrm{BM}=\mathrm{e}^{\mathrm{a}+\mathrm{b} * \ln (\mathrm{VO} 2 / \mathrm{BM}) \$}$ \\
\hline \multirow[t]{9}{*}{ Heart rate } & 3.1 & Zuurbier, $2009^{22}$ & Male: $\mathrm{VE}=\mathrm{e}^{1.03+(0.021 * \mathrm{HR})}$ \\
\hline & & & Female: $\mathrm{VE}=\mathrm{e}^{0.57+(0.023 * \mathrm{HR})}$ \\
\hline & 3.2 & Hart, $1998^{23}$ & $\mathrm{VE}=\mathrm{e}^{0.01894(\text { HR-HRrest })+0.01052(\text { Weight+1.9008) }}$ \\
\hline & 3.3 & Satoh, $1989^{24}$ & $\mathrm{VE}=10^{(9.38 *(\text { HR }- \text { HRrest })+4.22 * \text { Height }+1.19 * \text { Weight }+2.22 * \text { Age }+ \text { HRrest }) * 10^{-3}-0.0439}$ \\
\hline & 3.4 & Cozza, $2015^{25}$ & $\mathrm{VE}=\mathrm{e}^{0.58+(0.025 * \mathrm{HR})}$ \\
\hline & 3.5 & Ramos, $2015^{26}$ & Male: $\mathrm{VE}=\mathrm{e}^{1.17+(0.02 * \mathrm{HR})}$ \\
\hline & & & Female: $\mathrm{VE}=\mathrm{e}^{0.99+(0.02 * \mathrm{HR})}$ \\
\hline & 3.6 & Do Vale, $2015^{27}$ & $\mathrm{VE}=0.00071 * \mathrm{HR}^{2.17}$ \\
\hline & 3.7 & Greenwald, $2016^{28}$ & $\mathrm{VE}=(-3.859+(0.101 * \mathrm{HR})) * \mathrm{FVC}$ \\
\hline \multirow[t]{4}{*}{ Breathing rate } & 4.1 & McArdle, $2001^{29}$ & $\begin{array}{l}\mathrm{VT}=1.8028 * \ln (\mathrm{BR})-3.8881 \\
\mathrm{VE}=\mathrm{BR} * \mathrm{VT}\end{array}$ \\
\hline & 4.2 & Bigazzi and & $\mathrm{VT}=-0.5702+(16.454 *$ BRamplitude $)$ \\
\hline & & Figliozzi, $2015^{16}$ & $\mathrm{VE}=\mathrm{BR} * \mathrm{VT}$ \\
\hline & 4.3 & Greenwald, $2016^{28}$ & $\mathrm{VE}=(-1.913+(0.439 * \mathrm{BR})) * \mathrm{FVC}$ \\
\hline \multirow{2}{*}{$\begin{array}{l}\text { Heart rate and } \\
\text { breathing rate }\end{array}$} & 5.1 & Greenwald, $2016^{28}$ & $\mathrm{VE}=(-4.247+(0.0595 * \mathrm{HR})+(0.226 * \mathrm{BR})) * \mathrm{FVC}$ \\
\hline & 5.2 & Adams, $1993^{30}$ & Formulae per activity type (Supporting Information Table S2d) \\
\hline
\end{tabular}




\section{Analysis - Comparison of methods}

Different minute ventilation methods and inhaled doses were compared pairwise using several statistical metrics. Minute ventilation methods were compared on a minute by minute basis (all 1-minute data pooled), and on the aggregated level of a participant, i.e. average minute ventilation per person taking into account the time-activity pattern. Firstly, to assess the correlation between the methods, Pearson's correlation coefficients were calculated. Secondly, Lin's concordance correlation coefficients $\left(\rho_{c}\right)$ were determined, which assesses the correlation between the methods while accounting for the correspondence between methods in terms of absolute values ${ }^{31}$. Bland-Altman plots were generated; the mean difference between any two methods $\left(\mu_{\mathrm{d}}\right)$, and the correlation between the mean minute ventilation of two methods and the difference between the two methods $\left(\rho_{\mathrm{dm}}\right)$ were calculated ${ }^{32}$. Several sensitivity analyses were performed to check whether ventilation rate estimates varied across methods by type of activity, level of intensity, and between sexes or cities.

R-3.2.4 was used for data processing and analyses ${ }^{33}$. 


\section{Results}

General data

Participant characteristics are summarized in Table 2. $45 \%$ of our sample was male, with a median age of 34 years (range 18-61). All participants had a healthy BMI (22.8 \pm 2.8 , selfreported, at entry of the study). FVC was $3.9 \pm 0.6 \mathrm{~L}$ in females, and $5.4 \pm 0.7 \mathrm{~L}$ in males. Our sample consisted of relatively active and fit participants. Three participants stopped participation after one or two measurement weeks.

Table 2: Participant characteristics

\begin{tabular}{ll}
\hline Characteristics & All participants (N=122) \\
\hline City & \\
$\quad$ Antwerp (N) & 41 \\
Barcelona (N) & 41 \\
$\quad$ London (N) & 40 \\
Season & \\
$\quad$ Summer (N) & 120 \\
Intermediate (N) & 120 \\
Winter (N) & 121 \\
Male (\%) & 45 \\
Age, years [median (range)] & $34(18-61)$ \\
Caucasian (\%) & 94 \\
BMl (kg/m ${ }^{3}$ ) [mean \pm SD] & $22.8 \pm 2.8$ \\
&
\end{tabular}

Participants had on average $50 \pm 20$ hours of concurrent measurements with all devices, only during waking hours and spread over three seasons. Average resting heart rate in all participants was $76 \pm 14$ beats/min (Table 3). Heart rate while driving was on average $83 \pm 17$ beats/min, while road biking $104 \pm 27$ beats/min, and while walking $88 \pm 19$ beats/min. Heart rate during all other activities combined was $85 \pm 19$ beats/min. Breathing rate was highest while running ( $22 \pm 8$ breaths/min) and biking (21 \pm 7 breaths/min). The average resting breathing rate was $17 \pm 4$ breaths/min, while driving this increased to $18 \pm 5$ breaths/min and while walking to $20 \pm 7$ breaths/min. Minute by minute Pearson's correlation between heart rate and breathing rate was 0.27 . Breathing wave amplitude as measured by the Zephyr BioHarness is only indicative and it proved to be highly person-specific, most probably related to how participants wore the chest strap (location and tightness) ${ }^{16}$. Average METs values per activity type as estimated by the SenseWear monitor corresponded well to the reference values from Ainsworth et al. ${ }^{34}$. Mean black carbon exposure over all participants in coinciding time periods was $1636 \pm 673 \mathrm{ng} / \mathrm{m}^{3}$. Personal exposure to black carbon was significantly higher in Barcelona; and elevated concentrations were measured while travelling in all cities - all in line with previous studies ${ }^{35-37}$. In our dataset, the average black carbon exposure increased with increasing levels of physical activity, mainly driven by walking and cycling in urban areas 
close to traffic (METs <1.5: $B C=1391 \mathrm{ng} / \mathrm{m}^{3}$; METs 1.5-3: $\mathrm{BC}=1687 \mathrm{ng} / \mathrm{m}^{3}$; METs 3-6: $\mathrm{BC}=2180$ $\mathrm{ng} / \mathrm{m}^{3}$; METs >6: $\left.\mathrm{BC}=2261 \mathrm{ng} / \mathrm{m}^{3}\right)$. When FVC was larger, average breathing rate in that person tended to be lower, in men and women combined $(r=-0.36)$. A similar relationship was observed between FVC and heart rate $(r=-0.39)$.

Table 3: Mean $\pm S D$ of heart rate, breathing rate, breathing wave amplitude, and METs per activity.

\begin{tabular}{lllll}
\hline Activity type & $\begin{array}{l}\text { Heart rate* } \\
\text { [beats/min] }\end{array}$ & $\begin{array}{l}\text { Breathing rate* } \\
\text { [breaths/min] }\end{array}$ & $\begin{array}{l}\text { Breathing wave amplitude* } \\
\text { [V] }\end{array}$ & $\begin{array}{l}\text { METs } \\
\text { [b }\end{array}$ \\
\hline Sleeping (during daytime) & $73.0 \pm 17.2$ & $16.8 \pm 4.8$ & $53.4 \pm 79.0$ & $1.0 \pm 0.1$ \\
Resting & $76.2 \pm 14.5$ & $17.1 \pm 4.5$ & $60.6 \pm 93.0$ & $1.5 \pm 0.4$ \\
Motoring & $82.8 \pm 17.0$ & $18.3 \pm 5.0$ & $81.3 \pm 113.4$ & $1.5 \pm 0.8$ \\
Walking & $88.4 \pm 19.4$ & $20.2 \pm 6.9$ & $82.8 \pm 161.8$ & $3.7 \pm 1.0$ \\
Resistance & $88.4 \pm 18.1$ & $17.3 \pm 5.7$ & $91.7 \pm 122.9$ & $4.2 \pm 0.9$ \\
Stationary biking & $89.3 \pm 17.9$ & $17.9 \pm 6.1$ & $90.6 \pm 115.6$ & $6.3 \pm 1.5$ \\
Elliptical training & $92.8 \pm 24.1$ & $21.0 \pm 7.3$ & $59.7 \pm 56.6$ & $6.3 \pm 1.1$ \\
Running / brisk walking & $101.3 \pm 27.0$ & $22.0 \pm 8.0$ & $67.8 \pm 93.3$ & $6.8 \pm 2.0$ \\
Road biking & $104.3 \pm 27.4$ & $21.2 \pm 6.9$ & $105.3 \pm 114.3$ & $7.3 \pm 1.7$ \\
\hline
\end{tabular}

* Measured with the Zephyr BioHarness

\$ Measured with the SenseWear

\section{Minute ventilation}

Figure 1 illustrates the estimation of minute ventilation for one participant over one day, using the 16 different estimation methods. This particular test person rode a bicycle in the morning and evening and was at rest during working hours. Methods using the same input data were usually well correlated, although absolute values could differ. One exception was method 4.2 using the breathing wave amplitude from the Zephyr BioHarness; this method sometimes predicted negative values for minute ventilation which is impossible. 
(a) Breathing rate [breaths $/ \mathrm{min}]$, energy expenditure [kcal/min], and heart rate [beats $/ \mathrm{min}]$

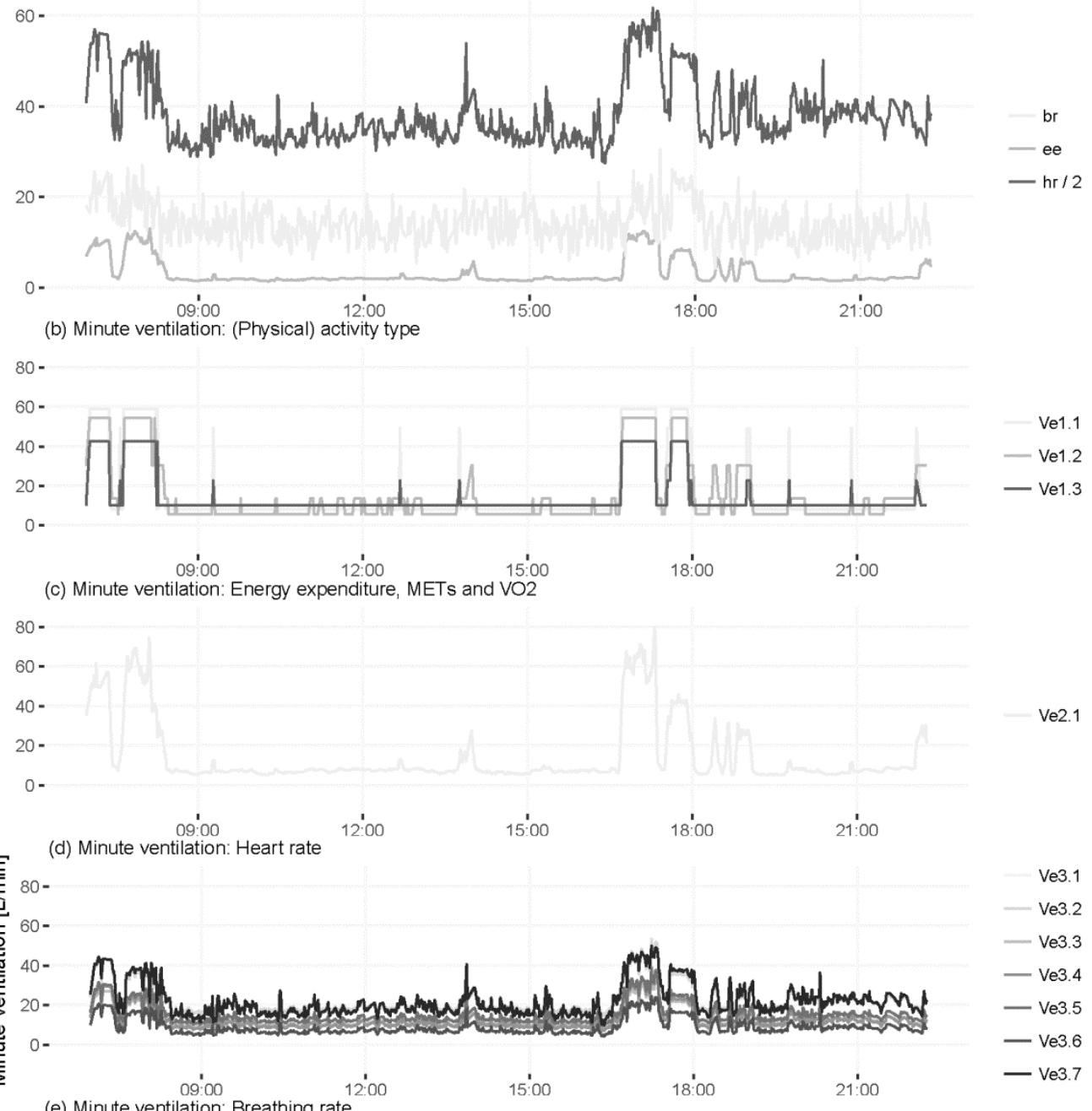

(e) Minute ventilation: Breathing rate

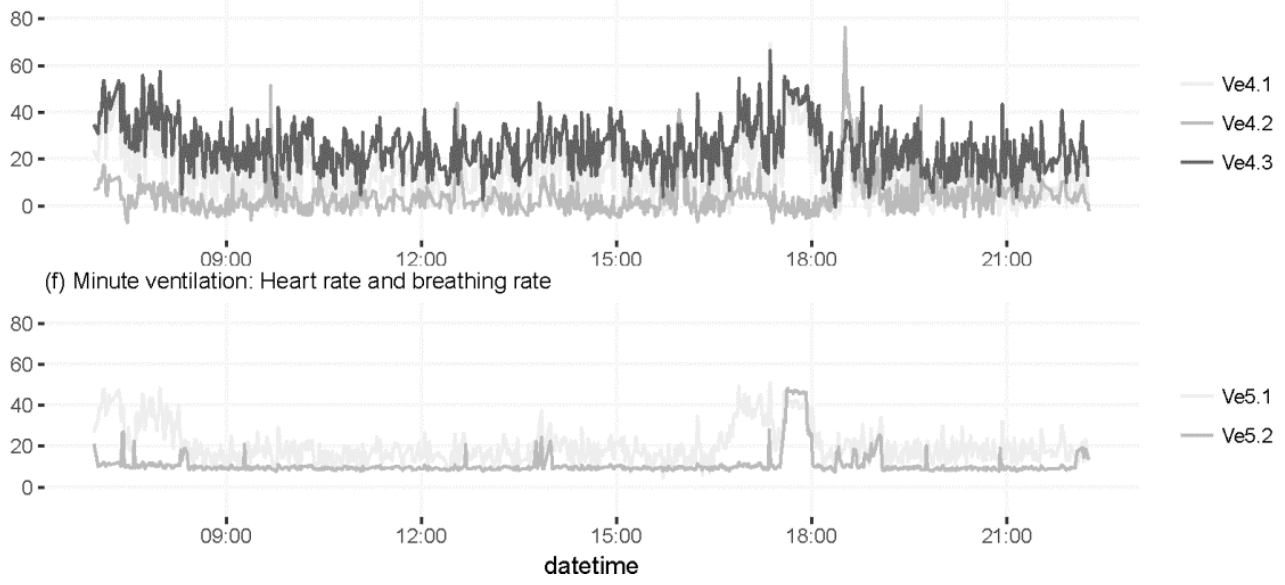

Figure 1: Top panel (a): Measurements of heart rate, breathing rate (both from Zephyr BioHarness) and energy expenditure (from SenseWear) for one participant over one day. Lower panels (b-f): Derived minute ventilation using 16 different formulae grouped by method (see Table 1 for formulae). 
Average minute ventilation per person using the different measures is shown in Figure $2 \mathrm{a}$. Methods Ve1.2 and Ve2.1 that both used METs as input data (the former as a categorical, the latter as a continuous variable) were well correlated, both on an aggregated person-level and on 1-minute data, and there was only a small systematic and proportional error $\left(\mu_{d}=-0.94\right.$ $\mathrm{L} / \mathrm{min}, \rho_{\mathrm{dm}}=-0.09$ on person-level). Method Ve1.3 correlated well with methods Ve1.1-2 (activity type) and Ve2.1 (energy expenditure, METs and VO2), but Lin's concordance correlation coefficient was lower $\left(\rho_{c}>0.33\right)$ due to the narrower range in predicted minute ventilations. The methods using heart rate data (Ve3.1-Ve3.7) showed a mutual maximum difference of a factor of two, and an average Pearson correlation coefficient of 0.58 . Comparisons between the heart rate methods differed quite a lot from the identity line, however, with an average Lin's concordance correlation coefficient of 0.33 , and a mean absolute difference of $4.12 \pm 2.58 \mathrm{~L} / \mathrm{min}$. The formulae of Hart ${ }^{23}$ (Ve3.2) resulted in higher predicted minute ventilations, while the function of Do Vale ${ }^{27}$ (Ve3.6) was at the lower end. The methods using breathing rate from the Zephyr BioHarness predicted the highest minute ventilations, except for method 4.2 that additionally used breathing wave amplitude. Method 4.2 had a very low concordance correlation coefficient compared to all other methods with $\rho_{c}<0.08$, and the Bland-Altman plots revealed proportional (mean $\rho_{\mathrm{dm}}$ close to 1 ) and systematic (mean $\mu_{d}=6.69 \pm 5.19 \mathrm{~L} / \mathrm{min}$ ) errors. A large variation was present in predicted ventilation rates. Methods Ve4.1 and Ve4.3 showed larger systematic errors (Ve4.1 mean $\mu_{d}=$ $9.58 \pm 4.06 \mathrm{~L} / \mathrm{min} ; \mathrm{Ve} 4.3$ mean $\mu_{d}=12.29 \pm 4.45 \mathrm{~L} / \mathrm{min}$ ), but the proportional error was somewhat smaller. Method Ve5.1 predicted elevated minute ventilation rates with a mean difference of $6.79 \pm 3.26 \mathrm{~L} / \mathrm{min}$. Only the most important correlations and differences between methods are discussed here; full correlation and difference matrices, and Bland-Altman plots are published in the Supporting Information Table S3-S6 and Figure S1. The same trends appeared when doing the analysis on 1-minute data rather than on person average data (Supporting Information Table S7-10). 


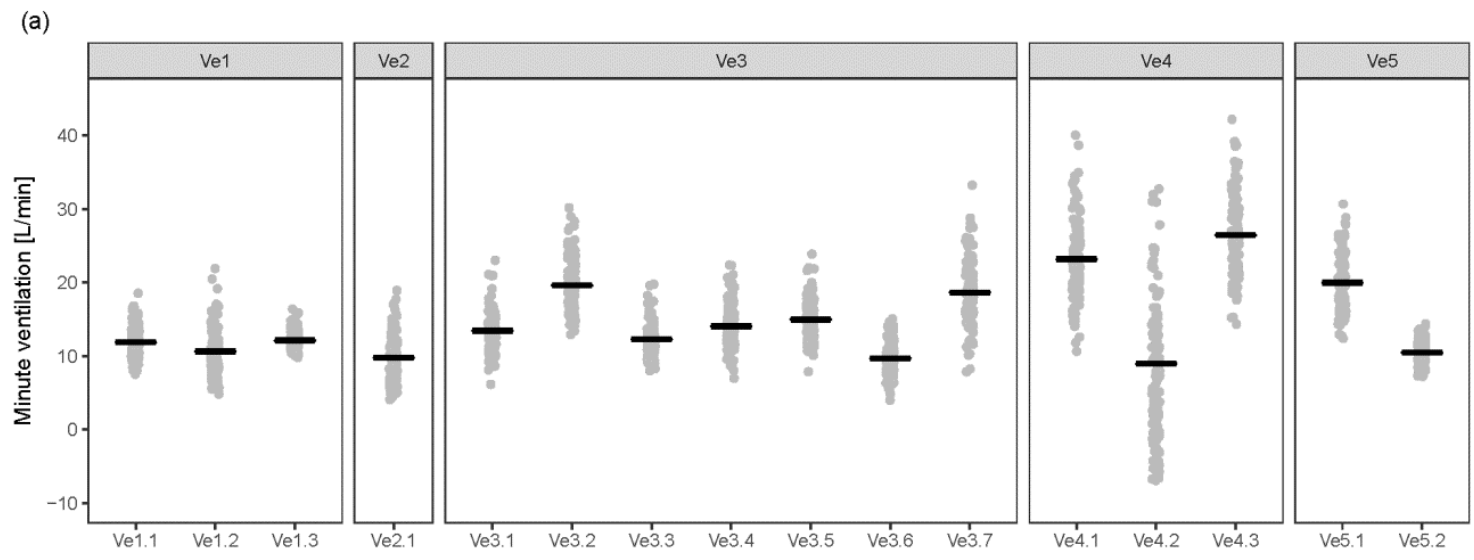

(b)

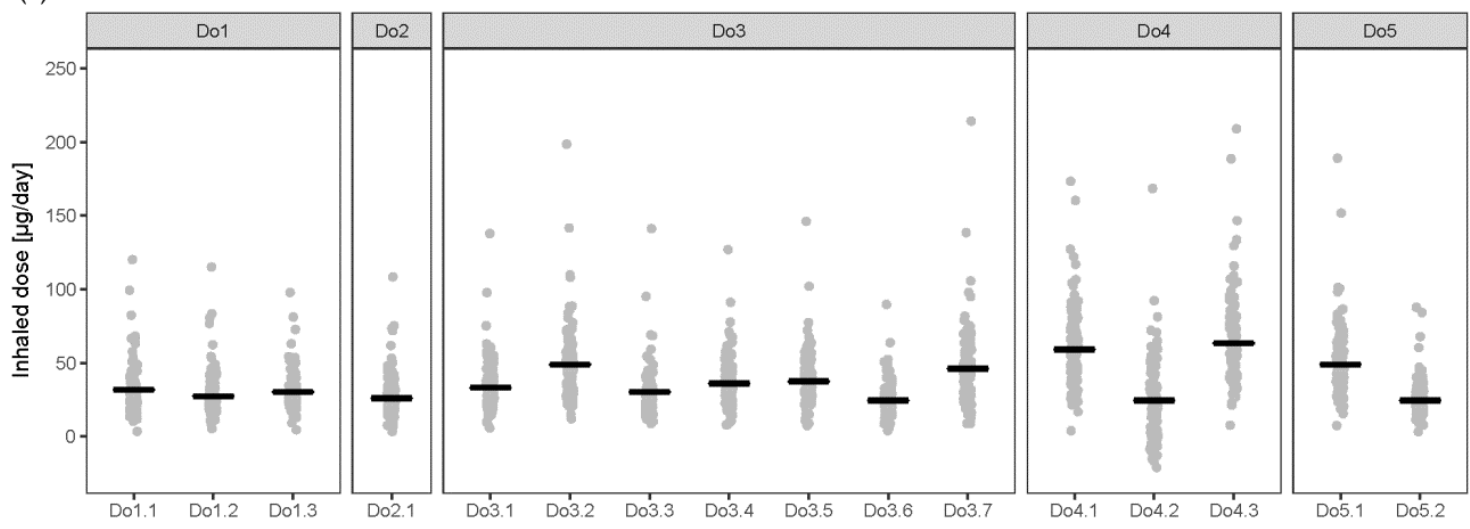

Figure 2: (a) Mean minute ventilation and (b) inhaled 24h black carbon dose per person of all participants ( $N=122)$ using 16 different methods (see Table 1 for formulae).

An analysis per activity type (Figure 3) and per physical activity level showed that methods Ve1.1, Ve1.2, Ve1.3, and Ve2.1 tended to give a lower minute ventilation estimate during lowMET activities compared to all other methods, while they gave a higher minute ventilation estimate when people were physically active (running, biking; METs>6). Within the heart rate method, ratios were consistent when looking at different activities separately: method Ve3.6 was at the lower end in general, but also per activity type this method was consistently lower. Highest minute ventilations were observed while cycling and running, and lowest while resting. Method Ve1.1 overestimated minute ventilation while walking by a factor of two when compared to all other methods; this should be adapted to better reflect walking at a moderate pace during a regular day. 


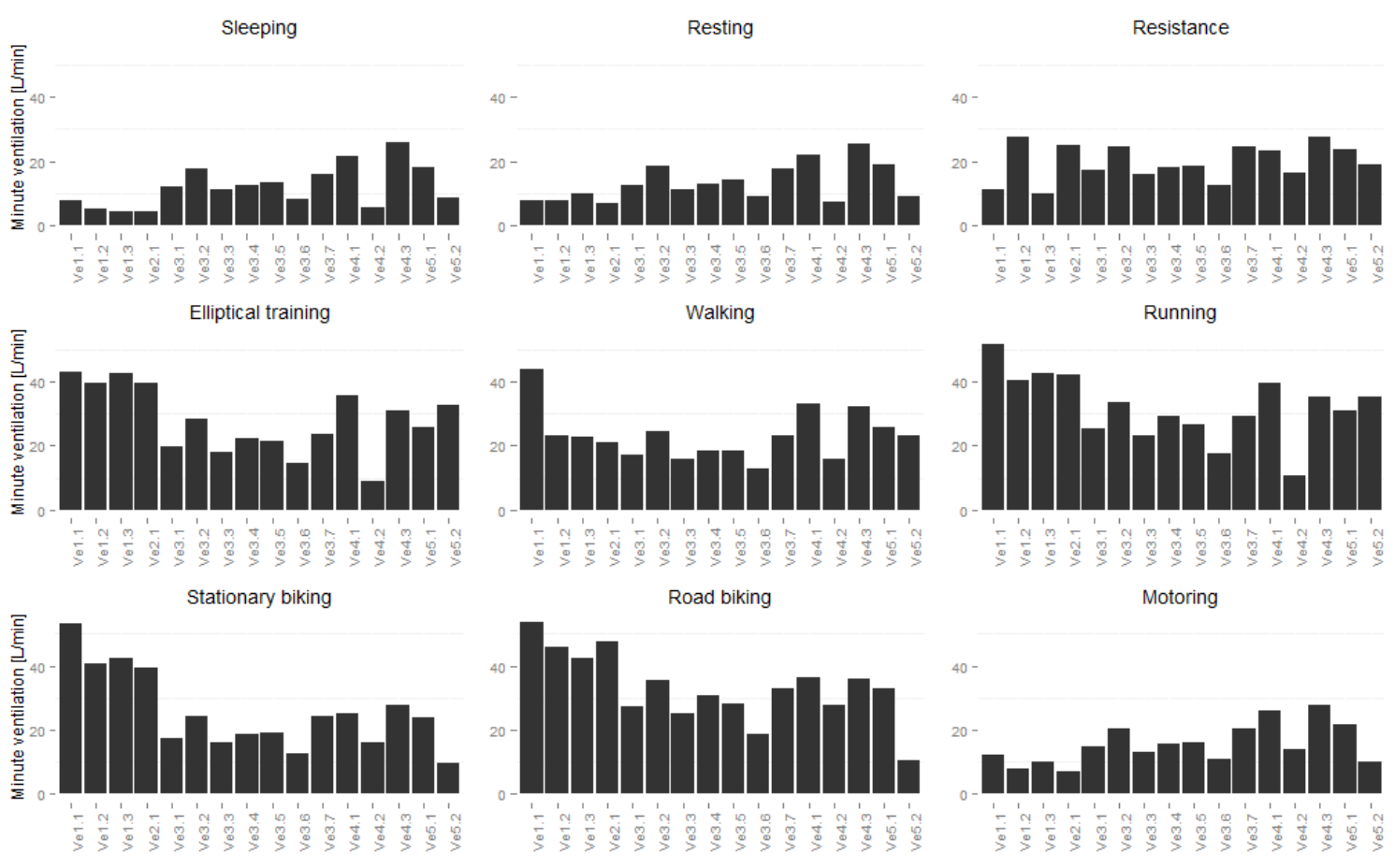

Figure 3: Comparison of ventilation estimates using 16 different formulae for different activity types and transport modes.

City or sex did not notably impact the ventilation estimates (Supporting Information Table S11), except for Ve4.2 that predicted lower ventilation in Barcelona and in males. Ventilation was slightly higher in Antwerp which can be explained by the higher share of male participants, possibly in combination with reported differences in cycling speed between the cities ${ }^{12,38,39}$. Four methods estimated higher average ventilation in women compared to men: Ve3.4, Ve3.6, Ve4.1, and Ve4.2. These were all methods that did not stratify between sexes, or did not include a variable like height, weight or FVC.

Inhaled dose

Inhaled black carbon dose was estimated for a $24 \mathrm{~h}$-period based on monitoring during waking hours only; therefore extrapolation to a full day will overestimate inhaled dose (lower ventilation and lower black carbon concentrations at night). When excluding method Ve4.2, doses estimated using the different methods correlated well $(r>0.54$ on aggregated personlevel; Supporting Information Table S12, S13), but absolute differences between methods mounted up to a factor of 2.6 (Table 4). The general trends compared well to the observations made for the estimation of minute ventilation (Figure $2 \mathrm{~b}$ ). 
Outliers (more than 2SD from the mean) were primarily due to high black carbon exposures, and not so much to high ventilation rates (Figure 2, Table 4). There were a few exceptions with individuals having normal black carbon levels combined with high average METs or heart rates, or relatively high black carbon combined with relatively high METs or heart rates.

When minute ventilation was assumed constant at $10 \mathrm{~L} / \mathrm{min}$ (similar to resting in HEAT ${ }^{21}$ ) and method Ve4.2 was excluded, dose will be underestimated by a factor 0.08 to 1.78 ( 2 to 42 $\mu \mathrm{g} / \mathrm{day})$ compared to when dynamic minute ventilation was being used.

Table 4: Mean minute ventilation and inhaled 24h black carbon dose per person of all participants ( $N=122$ ) using 16 different methods (see Table 1 for formulae).

\begin{tabular}{l|cc|cc}
\hline & \multicolumn{2}{|c|}{ Minute ventilation (L/min) } & \multicolumn{2}{c}{ Inhaled black carbon dose $(\mu \mathrm{g} /$ day $)$} \\
& Mean \pm SD & Min / max & Mean \pm SD & Min / max \\
\hline Ve1.1 & $11.7 \pm 2.3$ & $7.5 / 18.5$ & $31.5 \pm 16.5$ & $2.9 / 119.5$ \\
Ve1.2 & $10.4 \pm 3.2$ & $4.8 / 21.9$ & $27.9 \pm 15.6$ & $5.8 / 115.2$ \\
Ve1.3 & $12.0 \pm 1.3$ & $9.8 / 16.3$ & $30.4 \pm 13.4$ & $4.3 / 97.9$ \\
Ve2.1 & $9.4 \pm 3.1$ & $4.0 / 18.9$ & $25.4 \pm 15.0$ & $2.9 / 108.0$ \\
Ve3.1 & $13.3 \pm 2.8$ & $6.1 / 23.0$ & $34.6 \pm 16.9$ & $5.8 / 138.2$ \\
Ve3.2 & $19.5 \pm 3.5$ & $12.9 / 30.1$ & $49.7 \pm 24.2$ & $11.5 / 198.7$ \\
Ve3.3 & $12.2 \pm 2.3$ & $8.0 / 19.7$ & $31.4 \pm 16.2$ & $8.6 / 141.1$ \\
Ve3.4 & $14.0 \pm 3.1$ & $7.0 / 22.3$ & $36.9 \pm 17.4$ & $7.2 / 126.7$ \\
Ve3.5 & $14.9 \pm 2.6$ & $7.9 / 23.8$ & $38.2 \pm 17.8$ & $7.2 / 145.4$ \\
Ve3.6 & $9.7 \pm 2.2$ & $4.0 / 15.0$ & $25.3 \pm 12.0$ & $4.3 / 89.3$ \\
Ve3.7 & $18.3 \pm 4.6$ & $7.8 / 33.2$ & $47.3 \pm 25.4$ & $8.6 / 214.6$ \\
Ve4.1 & $23.2 \pm 5.8$ & $10.6 / 40.0$ & $60.7 \pm 26.4$ & $4.3 / 172.8$ \\
Ve4.2 & $8.3 \pm 12.7$ & $\mathrm{NA} / 87.2$ & $22.5 \pm 34.8$ & $\mathrm{NA} / 269.3$ \\
Ve4.3 & $26.1 \pm 5.5$ & $14.3 / 42.1$ & $65.3 \pm 29.9$ & $7.2 / 208.8$ \\
Ve5.1 & $19.7 \pm 3.8$ & $12.4 / 30.6$ & $50.7 \pm 24.2$ & $7.2 / 188.6$ \\
Ve5.2 & $10.3 \pm 1.6$ & $7.2 / 14.3$ & $25.8 \pm 12.6$ & $2.9 / 87.8$ \\
Fixed Ve & 10.0 & $10.0 / 10.0$ & $23.5 \pm 9.7$ & $4.3 / 79.2$ \\
\hline
\end{tabular}

* NA indicates an erroneous negative value. 


\section{Discussion}

This study aimed to evaluate methods to estimate the inhaled dose of air pollution. As no reference method exists, the aim was to understand the variability between different methods, and not to determine the best method. Methods considered included only technologies feasible for deployment in observational panel studies.

Methods using physical activity categories predicted comparable minute ventilation estimates over longer time periods compared to continuous methods, but substantial deviations (higher or lower estimates) existed during specific activities or when considering shorter time periods. Individual variation and changes in minute ventilation were better reflected when using continuous measures. Heart rate can be physiologically linked to ventilation, but several other factors also play a role: emotional stress, perceived risk, bated breathing, meteorological variables, traffic noise and activity nearby ${ }^{24,40-42}$. Using solely the heart rate signal to calculate dose can thus give unexpected results - especially at lower heart rate values below 90-100 bpm that are affected by the sympathetic nervous system ${ }^{41}$. Combining heart rate with accelerometry may improve the measurement of physical activity and the estimation of ventilation rates ${ }^{43,44}$. Heart rate changes tend to lead ventilation changes by around 20 seconds ${ }^{16}$ : taking into account our minimum time resolution of one minute, we decided to ignore this. Over longer averaging times, heart rate is expected to be the major determinant of minute ventilation ${ }^{11}$. According to Bernmark ${ }^{41}$ exponential functions to estimate minute ventilation from heart rate are to be preferred when considering longer time periods with varying heart rates; methods Ve3.6 and Ve3.7 were not exponential functions. Also, method Ve3.6 was originally developed on one person only; our study revealed that the formula is not universally valid and systematically gives lower minute ventilation estimates. Intuitively, breathing parameters are closest to minute ventilation. Breathing rate combined with tidal volume determines minute ventilation, but unobtrusive monitoring leads to uncertainty in both factors. Tidal volume can be determined from breathing rate (when breathing rate is higher, tidal volume is usually higher), or can be estimated from the breathing wave amplitude. The device used here, the Zephyr BioHarness, uses single band respiration through smart fabric sensors; this leads to more uncertainty compared to dual band systems. Tightness and location of the strap impact the measurement of breathing wave amplitude and breathing rate. Especially when using the formula with breathing wave amplitude from Bigazzi \& Figliozzi ${ }^{16}$, method Ve4.2, individual calibration is needed and should be considered an inherent part of this method making it impractical for large panel studies. Formulas for methods Ve3.7, Ve4.3 
and Ve5.1 were all developed by Greenwald on a sample of $15-18$ year olds ${ }^{28}$. In their analysis method Ve5.1, using both heart rate and breathing rate, outperformed methods Ve3.7 and Ve4.3. In our analysis all three methods predicted rather high minute ventilations, with method Ve5.1 in between the other two measures. Individual calibration of equations in laboratory exercise tests can improve the accuracy of the formulae as was done in many previous studies ${ }^{22,25,41}$. In larger panel studies this is not feasible and therefore only equations that were considered broadly valid and did not need individual calibration were compared here. There is some evidence for a feedback loop between ventilation and air pollution inhaled dose, in such that air pollution exposure may marginally augment or attenuate ventilation ${ }^{45}$, but it is not expected that this interaction will affect daily inhaled doses significantly, except in very highly polluted environments and in very active people ${ }^{46}$.

Mean daily inhaled doses in this study were slightly higher compared to values reported by de Nazelle ${ }^{36}$ and Rivas ${ }^{47}$ in Barcelona, Spain; though black carbon concentrations were similar. The elevated levels can be explained by the extrapolation we had to use due to the lack of nighttime measurements. Inhaled doses in Cassino, Italy ${ }^{48}$ and Shanghai, China ${ }^{49}$ are higher, but so were the concentrations. In our study, a few outliers were detected that were not reported in other studies; it concerned mainly very active people with high black carbon exposure.

In this paper, inhaled dose was defined as the concentration inhaled through the mouth or nose without taking into account air that is exhaled again or expelled from the respiratory tract lining. A variety of methods exist to more accurately determine the amount of particles reaching the target tissue, often described as the effective dose. Deposition models, like the human respiratory tract model developed by the International Commission for Radiological Protection (ICRP), calculate the deposited fraction in each part of the lung ${ }^{50-52}$. The effective dose is much less frequently studied in field studies in free-living populations, and only a few scripted studies have done this ${ }^{42,53,54}$. When physical effort plays a role in the study, the effective dose will be impacted by nasal/oral breathing patterns; moreover inter-individual differences in nasal/oral breathing make it hard to adjust for this in large panel studies ${ }^{46}$. The nose works as a filter, and more oral breathing leads to increased effective doses; though this holds mainly for larger particles and soluble vapours and not so much for black carbon ${ }^{26,46,55}$. Increased airflow can carry pollutants deeper into the respiratory tract into the lower airways, affecting deposited fraction and impact location ${ }^{55,56}$. An alternative approach to determine 
inhaled dose over longer time spans would be to use a dose biomarker, e.g. by sampling lower airway macrophages and analyse them for black carbon content ${ }^{57}$.

A limitation of this study is that ventilation was only assessed during waking hours as some of the sensors are not convenient to wear for 24 hours. For the same reason, facemasks or mouthpieces were not applied. A validation study could complement the current study, whereby the methods presented in this paper would be validated against facemask measurements during specific activities. We chose not to use an activity diary, but the timeactivity pattern was automatically determined by the SenseWear armband (based on accelerometry and propriety algorithms). The activity classification could be further improved by combining it with GPS data which we also collected. We did not quantitatively assess the exposure measurement error; in a population study Ragettli et al. ${ }^{58}$ showed that the size and sort of bias can change when either exposures or inhaled doses are used as exposure estimate in epidemiologic inference. The latter authors also showed that the size of the bias depends on the minute ventilation method used, suggesting that the choice for one method or another can significantly alter dose-response relationships in air pollution epidemiology. In these studies, it would be advisable to perform a sensitivity analysis, e.g. by testing the robustness of the effect while changing the inhaled dose estimate.

In our study, we have quantitatively evaluated the whole spectrum of existing methods to estimate inhaled dose and highlighted the differences between them. We have done so based on a large and unique dataset collected in three different cities over three different seasons, therefore covering a range of personal factors, meteorological and local conditions. This independent relative comparison of methods can therefore cast a new light on results obtained in previous studies that have used one of these methods (mostly without considering any other method). Based on our experimental set-up, we recommend not to use method Ve3.6 of Do Vale using heart rate (developed on one person only; not an exponential function), method Ve3.7 of Greenwald also using heart rate (not an exponential function) and method Ve4.2 using breathing rate (breathing wave amplitude needs individual calibration); and to reassess and lower the fixed minute ventilation for the activity type walking in method Ve1.1. In conclusion, differences between methods are present in absolute terms, but overall methods performed well in relative terms with high correlations among different methods pointing to a good level of consistency within methods. A systematic bias during a specific activity is problematic (e.g. walking in method Ve1.1) and this should be avoided. Given the 
good comparability of methods in relative terms, and given our observation that air pollution tends to be higher while physically active, we recommend the use of inhaled dose as an exposure metric in environmental epidemiology studies The choice of a suitable method to determine dose in future studies will depend both on the size and the objectives of the study. When the size of the study allows it, continuous methods using energy expenditure, heart rate or breathing rate should be preferred, but only when air pollution is monitored at a similar high temporal resolution. A heart and/or breathing rate monitor was considered more burdensome by volunteers than wearing a SenseWear armband or carrying a GPS making it impracticable for longer term monitoring, though recent advances like wrist-worn heart rate monitors may further reduce this burden. Considering all of the above and considering methods and devices available at the time of the study would favor method Ve2.1 using the SenseWear armband to determine energy expenditure and the formulas from Johnson ${ }^{20}$ to estimate minute ventilation. 


\section{Supporting information}

Literature review on minute ventilation methods; Additional information as a supplement with Table 1; Full correlation and difference matrices; Bland-Altman plots for method Ve2.1; Sensitivity analyses for sex and city.

\section{Acknowledgements}

This work was supported by the European project Physical Activity through Sustainable Transportation Approaches (PASTA). PASTA (http://www.pastaproject.eu/) is a four-year project funded by the European Union's Seventh Framework Program (EU FP7) under European Commission - Grant Agreement No. 602624. Evi Dons is supported by a postdoctoral scholarship from FWO - Research Foundation Flanders. Michelle Laeremans holds a joint PASTA/VITO PhD scholarship. 


\section{References}

1. HEI Traffic-related air pollution: A critical review of the literature on emissions, exposure, and health effects Special Report 17; Health Effects Institute: January 2010, 2010.

2. Steinle, S.; Reis, S.; Sabel, C. E., Quantifying human exposure to air pollution-Moving from static monitoring to spatio-temporally resolved personal exposure assessment. Sci. Total Environ. 2013, 443, 184-193.

3. Setton, E.; Marshall, J. D.; Brauer, M.; Lundquist, K. R.; Hystad, P.; Keller, P.; CloutierFisher, D., The impact of daily mobility on exposure to traffic-related air pollution and health effect estimates. J. Expo. Sci. Environ. Epidemiol. 2011, 21, (1), 42-48.

4. Mirowsky, J.; Gordon, T., Noninvasive effects measurements for air pollution human studies: methods, analysis, and implications. J. Expo. Sci. Environ. Epidemiol. 2015, 25, (4), 354380.

5. Koehler, K. A.; Peters, T. M., New methods for personal exposure monitoring for airborne particles. Curr. Environ. Health Rep. 2015, 2, (4), 399-411.

6. Nieuwenhuijsen, M. J.; Donaire-Gonzalez, D.; Foraster, M.; Martinez, D.; Cisneros, A., Using personal sensors to assess the exposome and acute health effects. Int. J. Environ. Res. Public Health 2014, 11, (8), 7805-7819.

7. Matt, F.; Cole-Hunter, T.; Donaire-Gonzalez, D.; Kubesch, N.; Martínez, D.; CarrascoTurigas, G.; Nieuwenhuijsen, M., Acute respiratory response to traffic-related air pollution during physical activity performance. Environ. Int. 2016, 97, 45-55.

8. Kubesch, N. J.; de Nazelle, A.; Westerdahl, D.; Martinez, D.; Carrasco-Turigas, G.; Bouso, L.; Guerra, S.; Nieuwenhuijsen, M. J., Respiratory and inflammatory responses to shortterm exposure to traffic-related air pollution with and without moderate physical activity. Occup. Environ. Med. 2015, 72, (4), 284-293.

9. Weichenthal, S.; Kulka, R.; Dubeau, A.; Martin, C.; Wang, D.; Dales, R., Traffic-related air pollution and acute changes in heart rate variability and respiratory function in urban cyclists. Environ. Health Perspect. 2011, 119, (10), 1373-8.

10. Tainio, M.; de Nazelle, A. J.; Götschi, T.; Kahlmeier, S.; Rojas-Rueda, D.; Nieuwenhuijsen, M. J.; de Sá, T. H.; Kelly, P.; Woodcock, J., Can air pollution negate the health benefits of cycling and walking? Prev. Med. 2016, 87, 233-236.

11. Mermier, C. M.; Samet, J. M.; Lambert, W. E.; Chick, T. W., Evaluation of the relationship between heart rate and ventilation for epidemiologic studies. Arch. Environ. Health 1993, 48, (4), 263-269.

12. Int Panis, L.; de Geus, B.; Vandenbulcke, G.; Willems, H.; Degraeuwe, B.; Bleux, N.; Mishra, V.; Thomas, I.; Meeusen, R., Exposure to particulate matter in traffic: A comparison of cyclists and car passengers. Atmos. Environ. 2010, 44, (19), 2263-2270.

13. Dons, E.; Gotschi, T.; Nieuwenhuijsen, M.; de Nazelle, A.; Anaya, E.; Avila-Palencia, I.; Brand, C.; Cole-Hunter, T.; Gaupp-Berghausen, M.; Kahlmeier, S.; Laeremans, M.; Mueller, N.; Orjuela, J. P.; Raser, E.; Rojas-Rueda, D.; Standaert, A.; Stigell, E.; Uhlmann, T.; Gerike, R.; Int Panis, L., Physical Activity through Sustainable Transport Approaches (PASTA): protocol for a multi-centre, longitudinal study. BMC Public Health 2015, 15, (1), 1126.

14. Ainsworth, B.; Cahalin, L.; Buman, M.; Ross, R., The current state of physical activity assessment tools. Prog. Cardiovasc. Dis. 2015, 57, (4), 387-395.

15. Hagler, G. S. W.; Yelverton, T. L. B.; Vedantham, R.; Hansen, A. D. A.; Turner, J. R., Postprocessing method to reduce noise while preserving high time resolution in aethalometer realtime black carbon data. Aerosol Air Qual. Res. 2011, 11, (5), 539-546.

16. Bigazzi, A. Y.; Figliozzi, M. A., Dynamic ventilation and power output of urban bicyclists. Transp. Res. Rec. 2015, (2520), 52-60.

17. Gerike, R.; de Nazelle, A.; Nieuwenhuijsen, M. J.; Int Panis, L.; Anaya, E.; Avila-Palencia, I.; Brand, C.; Cole-Hunter, T.; Dons, E.; Gaupp-Berghausen, M.; Kahlmeier, S.; Laeremans, M.; Mueller, N.; Orjuela, J. P.; Racioppi, F.; Raser, E.; Rojas-Rueda, D.; Schweizer, C.; Standaert, A.; 
Stigell, E.; Uhlmann, T.; Wegener, S.; Götschi, T., Physical Activity through Sustainable Transport Approaches (PASTA): a study protocol for a multicentre project. BMJ Open 2016, 6, (1), e009924.

18. Ott, W. R., Concepts of human exposure to air pollution. Environ. Int. 1982, 7, 179-196.

19. Dons, E.; Panis, L. I.; Van Poppel, M.; Theunis, J.; Wets, G., Personal exposure to Black Carbon in transport microenvironments. Atmos. Environ. 2012, 55, 392-398.

20. Johnson, T. A guide to selected algorithms, distributions, and databases used in exposure models developed by the office of air quality planning and standards; Research Triangle Park, North Carolina, 2002.

21. WHO Health economic assessment tools (HEAT) for walking and for cycling. [WWW Document]. http://www.euro.who.int/ data/assets/pdf file/0003/155631/E96097.pdf. (Accessed on August 18, 2016),

22. Zuurbier, M.; Hoek, G.; Hazel, P.; Brunekreef, B., Minute ventilation of cyclists, car and bus passengers: an experimental study. Environ. Health 2009, 8, (48).

23. Hart, C. K., Theory and evaluation of a new physiologic sampling pump. Department of Environmental Health, University of Washington: Seattle, 1998.

24. Satoh, T.; Higashi, T.; Sakurai, H.; Omae, K., Development of a new exposure monitoring system considering pulmonary ventilation (DEM 1). The Keio journal of medicine 1989, 38, (4), 432-42.

25. Cozza, I. C.; Zanetta, D. M. T.; Fernandes, F. L. A.; da Rocha, F. M. M.; de Andre, P. A.; Garcia, M. L. B.; Paceli, R. B.; Prado, G. F.; Terra-Filho, M.; Saldiva, P. H. d. N.; de Paula Santos, U., An approach to using heart rate monitoring to estimate the ventilation and load of air pollution exposure. Sci. Total Environ. 2015, 520, 160-167.

26. Ramos, C. A.; Reis, J. F.; Almeida, T.; Alves, F.; Wolterbeek, H. T.; Almeida, S. M., Estimating the inhaled dose of pollutants during indoor physical activity. Sci. Total Environ. 2015, 527, 111-118.

27. Do Vale, I. D.; Vasconcelos, A. S.; Duarte, G. O., Inhalation of particulate matter in three different routes for the same OD pair: A case study with pedestrians in the city of Lisbon. J. Transp. Health 2015, 2, (4), 474-482.

28. Greenwald, R.; Hayat, M. J.; Barton, J.; Lopukhin, A., A novel method for quantifying the inhaled dose of air pollutants based on heart rate, breathing rate and forced vital capacity. PLoS One 2016, 11, (1), e0147578.

29. McArdle, W. D.; Katch, F. I.; Katch, V. L., Exercise Physiology. Lippincott Williams \& Wilkins: Philadelphia, 2001; Vol. 5th Ed.

30. Adams, W. Measurement of breathing rate and volume in routinely performed daily activities; California Air Resources Board, California Environmental Protection Agency: Davis, California, 1993.

31. Lin, L. I., A concordance correlation coefficient to evaluate reproducibility. Biometrics 1989, 45, (1), 255-268.

32. Bland, J. M.; Altman, D. G., Statistical methods for assessing agreement between two methods of clinical measurement. Lancet 1986, 1, (8476), 307-310.

33. $\mathrm{R}$ Core Team $R$ : A language and environment for statistical computing, $\mathrm{R}$ Foundation for Statistical Computing: Vienna, Austria, 2016.

34. Ainsworth, B. E.; Haskell, W. L.; Herrmann, S. D.; Meckes, N.; Bassett, D. R.; TudorLocke, C.; Greer, J. L.; Vezina, J.; Whitt-Glover, M. C.; Leon, A. S., 2011 Compendium of physical activities: A second update of codes and MET values. Med. Sci. Sports Exerc. 2011, 43, (8), 1575-1581.

35. Dons, E.; Panis, L. I.; Van Poppel, M.; Theunis, J.; Willems, H.; Torfs, R.; Wets, G., Impact of time-activity patterns on personal exposure to black carbon. Atmos. Environ. 2011, $45,(21), 3594-3602$. 
36. de Nazelle, A.; Fruin, S.; Westerdahl, D.; Martinez, D.; Ripoll, A.; Kubesch, N.; Nieuwenhuijsen, M., A travel mode comparison of commuters' exposures to air pollutants in Barcelona. Atmos. Environ. 2012, 59, 151-159.

37. Jedynska, A.; Hoek, G.; Wang, M.; Eeftens, M.; Cyrys, J.; Keuken, M.; Ampe, C.; Beelen, R.; Cesaroni, G.; Forastiere, F.; Cirach, M.; de Hoogh, K.; De Nazelle, A.; Nystad, W.; Declercq, C.; Eriksen, K. T.; Dimakopoulou, K.; Lanki, T.; Meliefste, K.; Nieuwenhuijsen, M. J.; Yi-Tuomi, T.; Raaschou-Nielsen, O.; Brunekreef, B.; Kooter, I. M., Development of land use regression models for elemental, organic carbon, PAH, and hopanes/steranes in 10 ESCAPE/TRANSPHORM European study areas. Environ. Sci. Technol. 2014, 48, (24), 1443514444.

38. Cole-Hunter, T.; Morawska, L.; Stewart, I.; Jayaratne, R.; Solomon, C., Inhaled particle counts on bicycle commute routes of low and high proximity to motorised traffic. Atmos. Environ. 2012, 61, 197-203.

39. Zuurbier, M.; Hoek, G.; Oldenwening, M.; Lenters, V.; Meliefste, K.; van den Hazel, P.; Brunekreef, B., Commuters' exposure to particulate matter air pollution is affected by mode of transport, fuel type, and route. Environ. Health Perspect. 2010, 118, (6), 783-9.

40. Doorley, R.; Pakrashi, V.; Byrne, E.; Comerford, S.; Ghosh, B.; Groeger, J. A., Analysis of heart rate variability amongst cyclists under perceived variations of risk exposure. Transportation Research Part F: Traffic Psychology and Behaviour 2015, 28, 40-54.

41. Bernmark, E.; Wiktorin, C.; Svartengren, M.; Lewne, M.; Aberg, S., Bicycle messengers: energy expenditure and exposure to air pollution. Ergonomics 2006, 49, (14), 1486-95.

42. Nyhan, M.; McNabola, A.; Misstear, B., Comparison of particulate matter dose and acute heart rate variability response in cyclists, pedestrians, bus and train passengers. Sci. Total Environ. 2014, 468-469, 821-831.

43. Brage, S.; Ekelund, U.; Brage, N.; Hennings, M. A.; Froberg, K.; Franks, P. W.; Wareham, N. J., Hierarchy of individual calibration levels for heart rate and accelerometry to measure physical activity. J. Appl. Physiol. 2007, 103, (2), 682-692.

44. Villars, C.; Bergouignan, A.; Dugas, J.; Antoun, E.; Schoeller, D. A.; Roth, H.; Maingon, A. C.; Lefai, E.; Blanc, S.; Simon, C., Validity of combining heart rate and uniaxial acceleration to measure free-living physical activity energy expenditure in young men. J. Appl. Physiol. 2012, 113, (11), 1763-1771.

45. Giles, L. V.; Brandenburg, J. P.; Carlsten, C.; Koehle, M. S., Physiological responses to diesel exhaust exposure are modified by cycling intensity. Med. Sci. Sports Exerc. 2014, 46, (10), 1999-2006.

46. U.S.EPA Physiological parameters and physical activity data for evaluating exposure modeling performance: a synthesis; EPA/600/R-15/175; Office of Research and Development National Exposure Research Laboratory: Washington, DC, 2015.

47. Rivas, I.; Donaire-Gonzalez, D.; Bouso, L.; Esnaola, M.; Pandolfi, M.; de Castro, M.; Viana, M.; Alvarez-Pedrerol, M.; Nieuwenhuijsen, M.; Alastuey, A.; Sunyer, J.; Querol, X., Spatiotemporally resolved black carbon concentration, schoolchildren's exposure and dose in Barcelona. Indoor Air 2016, 26, (3), 391-402.

48. Buonanno, G.; Stabile, L.; Morawska, L.; Russi, A., Children exposure assessment to ultrafine particles and black carbon: The role of transport and cooking activities. Atmos. Environ. 2013, 79, 53-58.

49. Lei, X.; Xiu, G.; Li, B.; Zhang, K.; Zhao, M., Individual exposure of graduate students to PM2.5 and black carbon in Shanghai, China. Environ. Sci. Pollut. Res. Int. 2016, 23, (12), $12120-$ 7.

50. Buonanno, G.; Giovinco, G.; Morawska, L.; Stabile, L., Tracheobronchial and alveolar dose of submicrometer particles for different population age groups in Italy. Atmos. Environ. 2011, 45, (34), 6216-6224. 
51. McNabola, A.; Broderick, B. M.; Gill, L. W., Relative exposure to fine particulate matter and VOCs between transport microenvironments in Dublin: Personal exposure and uptake. Atmos. Environ. 2008, 42, (26), 6496-6512.

52. ICRP Annals of the International Commission for Radiological Protection, human respiratory tract model for radiological protection, 24. ICRP Publication 66; 1994; pp 1-3.

53. Löndahl, J.; Massling, A.; Swietlicki, E.; Bräuner, E. V.; Ketzel, M.; Pagels, J.; Loft, S., Experimentally Determined Human Respiratory Tract Deposition of Airborne Particles at a Busy Street. Environ. Sci. Technol. 2009, 43, (13), 4659-4664.

54. Mazaheri, M.; Clifford, S.; Jayaratne, R.; Megat Mokhtar, M. A.; Fuoco, F.; Buonanno, G.; Morawska, L., School Children's Personal Exposure to Ultrafine Particles in the Urban Environment. Environ. Sci. Technol. 2014, 48, (1), 113-120.

55. Carlisle, A.; Sharp, N., Exercise and outdoor ambient air pollution. Br. J. Sports Med. 2001, 35, (4), 214-222.

56. Daigle, C. C.; Chalupa, D. C.; Gibb, F. R.; Morrow, P. E.; Oberdorster, G.; Utell, M. J.; Frampton, M. W., Ultrafine particle deposition in humans during rest and exercise. Inhal. Toxicol. 2003, 15, (6), 539-552.

57. Nwokoro, C.; Ewin, C.; Harrison, C.; Ibrahim, M.; Dundas, I.; Dickson, I.; Mushtaq, N.; Grigg, J., Cycling to work in London and inhaled dose of black carbon. Eur. Respir. J. 2012, 40, (5), 1091-1097.

58. Ragettli, M. S.; Phuleria, H. C.; Tsai, M. Y.; Schindler, C.; de Nazelle, A.; Ducret-Stich, R. E.; Ineichen, A.; Perez, L.; Braun-Fahrlander, C.; Probst-Hensch, N.; Kunzli, N., The relevance of commuter and work/school exposure in an epidemiological study on traffic-related air pollution. J. Expo. Sci. Environ. Epidemiol. 2015, 25, (5), 474-81. 